\title{
Chapter 1 \\ Path and the Standards of Rural School \\ Consolidation in China Since 2000
}

\author{
Zhihui Wu
}

The one-child policy implemented by governments in China since 1971 and the large-scale migration of people from the countryside to cities since the 1980s have led to a natural reduction in number and space flow of school-aged children in the countryside. This has compelled education departments to promote a larger scale of rural school closure and consolidation. Closure and consolidation of rural primary and middle schools ${ }^{1}$ in China exhibit the following macro features. ${ }^{2}$ First, the scale of rural school closure and consolidation was the largest in the first 10 years of the twenty-first century (or 2000-2010). From 1976 to 2016, approximately 946,100 compulsory schools including primary and middle schools disappeared. A total of 386,500 schools among them were shut down between 2000 and 2016, accounting for $41 \%$ of the total number of schools that disappeared in the past 40 years. On average, approximately 66 schools disappeared every day. Moreover, from 2000 to 2010, the decrease in the number of schools was the highest (about 304,100 schools), and approximately 83 schools were closed every day on average. Second, school consolidation has primarily occurred in rural areas since 2000. A total of 357,000 compulsory schools that disappeared after 2000 were rural schools, accounting for $92.36 \%$ of the total number (about 386,500 schools). Approximately 61 compulsory schools in the countryside were shut down every day. Third, rural primary schools were the main target of school consolidation. A total of 333,900 primary schools in

\footnotetext{
${ }^{1}$ In China, the school system of 9-year compulsory education is of two types. In most provinces, the primary school comprises Grades 1-6, and middle school comprises Grades 7-9. In some provinces, the primary school comprises Grades 1-5, and the middle school comprises Grades 6-9.

${ }^{2}$ The following data are the results of the data presented in Educational Statistics Yearbook of China (2000-2016) (中国教育统计年鉴) and Statistics Yearbook of China (中国统计年鉴).
}

\footnotetext{
$\mathrm{Z} . \mathrm{Wu}(\bowtie)$ University, Changchun, Jilin Province, China e-mail:wuzh@nenu.edu.cn

Graduate School and China Institute of Rural Education Development, Northeast Normal 
rural areas were closed, accounting for $93.53 \%$ of the total decreasing number of rural schools (about 357,000) and $86.39 \%$ of the total decreasing number of schools in urban and rural areas. Why did rural schools disappear rapidly after 2000? What is the development trend? What are the standards for rural school closure and consolidation in China? These are the research questions to be addressed in the chapter.

\subsection{Background}

\subsubsection{The Educational Management System Reform Provides Rural School Consolidation with Institutional Space}

In order to alleviate the financial burden of farmers, governments began to explore and implement tax reforms in rural areas, such as abolishing the educational tax ${ }^{3}$ and strictly prohibiting schools or other departments from levying extra fees from farmers after 2000. Paradoxically the educational tax in the countryside is an important source of funds for compulsory rural education, accounting for approximately $30 \%$ of the total rural education expenditure. In order to alleviate the financial pressure of governments at the township or town level in a system where schools are operated and managed by governments at different levels, ${ }^{4}$ the State Council made a major change to the management system of rural compulsory education in 2001 . The main change was that the government of the county had to take the main responsibility for compulsory education instead of the government of the Xiang (or township). This change has shifted the cost of rural compulsory education from farmers to governments and from the township or town government to the county government. Since the implementation of the new management system, the county government is motivated to improve the financial situation and the efficiency of the resources utilization through school consolidation. After the reform of the taxsharing system, ${ }^{5}$ the main fiscal expenditure of many county-level governments is

\footnotetext{
${ }^{3}$ Rural areas have two types of educational tax. The first one is called "raising funds for rural education” (农村教育集资). It means that governments of towns or Xiangs (townships) can raise funds for the construction of schools or repairing of school buildings from some companies, social groups, or individuals. The second one is called “extra fees of rural education” (农村教育费附加). In the last century, governments of Xiang should take the whole responsibility of compulsory education, such as financial responsibility. Some governments in developing areas can levy "extra educational fees" to improve the budget constraint to develop the rural education.

${ }^{4}$ The system by which schools are run and managed by governments at different levels was the main management institution of education before 2001. It meant that local governments had to take complete responsibility for local schools, and the government at a higher level may not transfer extra money to local government. For example, before 2001, the township or town government had to cover the running cost of all rural schools in their district.

${ }^{5}$ The reform of the tax-sharing system in China was introduced in 1993. According to the Decisions on the Implementation of the Fiscal Management System of the Tax-Sharing System (关于实行分 税制财政管理体制的决定) issued by the State Council in 1993, the range of fiscal expenditure
} 
the salary of public employees, and some governments even had to take a loan to cover the running cost. ${ }^{6}$ Some county governments may find it difficult to afford a large amount of compulsory education expenditure, so they are compelled to close or consolidate some rural schools out of the fiscal pressure.

\subsubsection{The Shift of Universal Education to High-Quality Education Provides Rural School Consolidation with Policy Background}

Offering universal compulsory education was the most important target of educational development in China before 2000. According to the Compulsory Education Law of the People's Republic of China (中华人民共和国义务教育法) in 1986, China implemented 9-year compulsory education, and the local governments at all levels were required to set up an adequate number of primary schools and secondary schools to help children travel a short distance to school. Moreover, the Outline of China's Education Reform and Development(中国教育改革和发展纲要) issued by the State Council in 1993 also revealed that at the stage of generalizing education, the main aim of governments was to provide adequate educational opportunities for school-aged children and ensure that they could go to school conveniently. Hence, the central governments required the whole country to maintain a certain number of schools and asked for a reasonable distribution of schools. More specifically, from 1986 to 2000, the number of primary schools in China ranged from 500,000 to 800,000 , and the number of small-scale schools ${ }^{7}$ was about 170,000 .

The Decision on the Reform and Development of Elementary Education (关于基 础教育改革和发展的决定) issued by the State Council in 2001 affirmed that rural school closure and consolidation should be promoted based on local conditions. Local governments were responsible for planning and building schools within

would be divided based on the different responsibilities of the local and central governments. The tax would be classified into three types, including national tax, local tax, and sharing tax.

${ }^{6}$ The provincial government of Anhui conducted a survey of the fiscal situation in 2001 and 2002. The survey showed that in 2001, the government revenues and fiscal expenditure of seven counties (including Shouxian, Jinzhai, Fengyang, Guzhen Lujiang, Nanling, and Ningguo) were 163 million and 295 million, 98 million and 224 million, 106 million and 204 million, 118 million and 220 million, 191 million and 312 million, 138 million and 186 million, and 288 million and 240 million, respectively. In 2002, they were 154 million and 304 million, 106 million and 238 million, 110 million and 210 million, 97 million and 207 million, 266 million and 324 million, 159 million and 207 million, and 332 million and 291 million, respectively. Hence, the fiscal expenditure was higher that the government receipts in six counties excepting Ningguo (Hu and Zhang 2007, p. 7-8).

${ }^{7}$ According to The Opinions on Comprehensive Strengthening of the Construction of Small-Scale Schools in the Countryside and Boarding Schools in the Town or Township (关于全面加强乡村小 规模学校和乡镇寄宿制学校建设的指导意见) issued by the State Council, small-scale schools in the countryside refer to those schools that have fewer than 100 students (2018). 
appropriate distance to students' homes. Rural primary schools and small-scale schools should be appropriately consolidated by the criteria of travelling convenience. In some areas where the traffic conditions were poor, it was necessary for governments to maintain a reasonable number of small-scale schools to prevent students from dropping out of schools due to the long and inconvenient travel. Moreover, governments can build boarding schools to meet students' needs. In such policy contexts, layout and scale of rural schools have become one of the key concerns in rural educational reform.

\subsubsection{Urbanization Offers Strategic Expectations for Rural School Consolidation}

In 1996, the urbanization rate of China reached about $30 \%$ and rose to $57.35 \%$ in 2016. From 2000 to 2016, the urban population increased by 334 million and reached 793 million. After the Third Plenary Session of the 15th Central Committee of Communist Party of China (中国共产党第十五届三中全会) in 1998, many townships and towns were merged together. By the end of 2016, the number of townships reduced to 10,872 , and the total number of towns and townships decreased from 97,521 in 1984 to 31,755 in 2016 . In other words, approximately $66 \%$ of towns and townships disappeared.

As a result, the traditional layout of rural schools, i.e., every village with a primary school, every township with a middle school, and every town or county with a high school, faced new challenges. Based on the estimation of the future decreasing population in the rural areas, a new school layout emerged in which primary schools are mainly established in towns or townships and middle schools are mainly established in towns or county towns. This new structure will be the strategic expectation that adapts to the development trend of urbanization in the next 20 years.

\subsubsection{The Decrease in the Number of Students in Rural Schools as an Objective Basis for Rural School Consolidation}

Since 2000, the number of newborn babies in rural areas has decreased by 3,704,400 (about 32.66\% of the figure in 2000), from 11,341,400 in 2000 to 7,637,000 in 2016. Because of the wide distribution of the rural population's residence, with the rapid decline in the number of rural students, the traditional layout of rural education (every village having a primary school) has been challenged. Many schools have less than 50 students. Moreover, some local governments have raised funds to construct a large number of schools. Owing to excessive construction, many rural schools have two students taught by ten teachers now, and some rural schools do not 
even have students. There are a great number of small-scale schools (also called Sparrow Schools or Empty-Nest Schools) in rural areas. The decline in the total number of rural students has directly led to the large-scale closure and consolidation of rural schools.

\subsection{Path of Rural School Consolidation After 2000}

After analyzing the complete process of rural school consolidation, this study identifies the path as following.

\subsubsection{Faster Decline Rate of the Number of Rural Schools}

According to national statistics, the number of primary schools in the counties reduced from 521,500 in 2000 to 151,000 in 2016, decreasing by 370,500 (approximately $71.05 \%$ of the figure in 2000). Among them, the number of primary schools in towns (including towns and county towns) declined from 81,200 in 2000 to 44,600 in 2016, decreasing by 36,600 (approximately $45.07 \%$ of the figure in 2000 and $9.88 \%$ of the total decreasing number of primary schools in counties). On the other hand, the number of rural primary schools declined from 440,300 in 2000 to 106,400 in 2016 , decreasing by 333,900 (approximately $75.83 \%$ of the figure in 2000 and $90.12 \%$ of the total decreasing number of primary schools in counties).

Compared to the number of primary schools, the number of small-scale schools presents a different development trend (first decreasing and then increasing). The number of small-scale schools in the counties reduced from 172,600 in 2000 to 66,600 in 2011. This considerable decline in the number of rural small-scale schools has a huge negative effect on rural education. For instance, several countryside students have to travel a longer distance to school, which may cause more traffic accidents and result in a heavy economic burden on the students' family. Moreover, the decrease in the number of rural small-scale schools may also result in a shortage of boarding schools and the problem of large-size classes in urban schools.

In 2012, in order to solve those problems, the General Office of the State Council issued the Opinions on Regulating the Layout Adjustment to Compulsory Education Schools in Rural Areas (关于规范农村义务教育学校布局调整的意见). It states that rural primary schools and small-scale schools should be run effectively by local governments. Since then, the number of small-scale schools increased from 66,600 in 2011 to 96,900 in 2016. However, from the perspective of the overall development trend, in the past 16 years (2000-2016), the total number of smallscale schools has decreased by 75,700 (approximately $43.86 \%$ of the number in 2000). Among them, the number of small-scale schools in towns (including towns and county towns) decreased from 15,100 in 2000 to 1300 in 2010 and increased to 10,100 in 2016. In other words, from 2000 to 2016, the figure decreased by 5000 
Table 1.1 The number of primary schools and small-scale schools in counties between 2000 and 2016 (Unit: 10,000 schools)

\begin{tabular}{l|l|l|l|l|l|l}
\hline & \multicolumn{3}{l}{ Primary schools in counties } & \multicolumn{3}{l}{ Small-scale schools in counties } \\
\cline { 2 - 7 } & Town & Village & Total & Town & Village & Total \\
\hline 2000 & 8.12 & 44.03 & 52.15 & 1.51 & 15.75 & 17.26 \\
\hline 2001 & 4.88 & 41.62 & 46.5 & 0.32 & 11.04 & 11.36 \\
\hline 2002 & 4.69 & 38.40 & 43.09 & 0.34 & 10.83 & 11.16 \\
\hline 2003 & 4.00 & 36.04 & 40.04 & 0.32 & 10.17 & 10.49 \\
\hline 2004 & 3.34 & 33.73 & 37.07 & 0.26 & 9.81 & 10.07 \\
\hline 2005 & 2.91 & 31.68 & 34.59 & 0.12 & 9.30 & 9.42 \\
\hline 2006 & 2.96 & 29.51 & 32.47 & 0.15 & 8.76 & 8.91 \\
\hline 2007 & 3.09 & 27.16 & 30.25 & 0.16 & 8.31 & 8.47 \\
\hline 2008 & 3.05 & 25.30 & 28.35 & 0.13 & 7.75 & 7.89 \\
\hline 2009 & 2.97 & 23.42 & 26.38 & 0.13 & 7.10 & 7.23 \\
\hline 2011 & 3.01 & 21.09 & 24.10 & 0.13 & 6.54 & 6.67 \\
\hline 2012 & 4.60 & 16.90 & 21.50 & 0.56 & 6.10 & 6.66 \\
\hline 2013 & 4.72 & 15.50 & 20.24 & 0.64 & 6.25 & 6.90 \\
\hline 2014 & 4.64 & 14.03 & 18.75 & 0.81 & 7.36 & 8.16 \\
\hline 2015 & 4.61 & 12.87 & 17.51 & 0.90 & 7.86 & 8.76 \\
\hline 2016 & 4.46 & 10.64 & 15.10 & 1.01 & 8.68 & 9.69 \\
\hline
\end{tabular}

Data Source: The Department of Development, and Planning, Ministry of Education (20012017). Zhongguo jiaoyu tongji nianjian (2000-2016) [Educational Statistics Yearbook of China (2000-2016)], Beijing: People's Education Press

Note: Town includes the town and the county town

(approximately $33.11 \%$ of the figure in 2000 and $6.61 \%$ of the total decline number of small-scale primary schools in the county). Moreover, the number of rural smallscale primary schools declined from 157,500 in 2000 to 61,000 in 2011 and then rose to 86,800 in 2016 , decreasing by 70,700 (approximately $44.89 \%$ of the figure in 2000 and $93.39 \%$ of the total decreasing number of primary schools in the county). Overall, the total number of primary schools and small-scale schools in counties nationwide dropped from 694,100 in 2000 to 247,900 in 2016, decreasing by 446,200 (approximately $64.28 \%$ of the figure in 2000) (see Table 1.1).

The decline rate of the number of students enrolled in schools was different from that of schools. The number of students enrolled in primary schools in counties nationwide dropped from 112 million in 2000 to 66 million in 2016, decreasing by $45,507,700$ (approximately $40.64 \%$ of the figure in 2000). The decline rate of the number of primary schools and small-scale schools in the counties $(64.28 \%)$ was 1.58 times the decline rate of the number of students enrolled in primary schools in counties (40.64\%), and the difference between those was $23.64 \%$ (see Table 1.2).

As for the variation in the number of middle schools, ${ }^{8}$ the number of middle schools in counties declined from 54,000 in 2000 to 40,200 in 2016, decreasing by

\footnotetext{
${ }^{8}$ There are many types of middle schools in China, such as the 9-year school (including the primary school and middle school) and secondary school (including the middle school and senior
} 
Table 1.2 The number of students enrolled in primary schools in counties (Unit: 10,000 people)

\begin{tabular}{l|l|l|l}
\hline Year & Town & Village & Total \\
\hline 2000 & 2692.89 & 8503.71 & 11196.60 \\
\hline 2001 & 2257.79 & 8604.80 & 10862.59 \\
\hline 2002 & 2293.77 & 8141.68 & 10435.45 \\
\hline 2003 & 2192.90 & 7689.15 & 9882.05 \\
\hline 2004 & 2036.23 & 7378.60 & 9414.83 \\
\hline 2005 & 2185.86 & 6947.83 & 9133.69 \\
\hline 2007 & 2431.82 & 6676.14 & 9107.96 \\
\hline 2008 & 2552.19 & 6250.73 & 8802.92 \\
\hline 2009 & 2602.25 & 5924.88 & 8527.13 \\
\hline 2010 & 2637.15 & 5655.54 & 8292.70 \\
\hline 2011 & 2770.02 & 5350.22 & 8120.24 \\
\hline 2013 & 3254.21 & 4065.20 & 7319.41 \\
\hline 2014 & 3354.98 & 3652.49 & 7007.47 \\
\hline 2015 & 3370.54 & 3217.04 & 6587.58 \\
\hline 2016 & 3457.96 & 3049.86 & 6507.82 \\
\hline
\end{tabular}

Data Source: The Department of Development, and Planning, Ministry of Education (20012017). Zhongguo jiaoyu tongji nianjian (2000-2016) [Educational Statistics Yearbook of China (2000-2016)], Beijing: People's Education Press

Note: Town includes the town and the county town

13,797 (approximately $25.55 \%$ of the figure in 2000). Although the decrease in the number of middle schools in counties was not very large, the variation is significant by considering the change in the types of schools, such as middle schools in towns (including towns and county towns) and in villages. That is, the number of middle schools in villages declined, and those in towns rose (see Table 1.3) from 14,700 in 2000 to 24,000 in 2016. In contrast, the number of middle schools in villages declined from 39,300 in 2000 to 16,200 in 2016, decreasing by 23,142 (approximately $58.87 \%$ of the figure in 2000).

Compared to the change in the number of students enrolled in middle schools in counties, the variation in the number of middle schools is more considerable. ${ }^{9}$ The

middle school). Therefore, when we calculate the total number of middle schools, we count both 9 -year schools and secondary schools because those include middle schools. Moreover, because of the change of the statistic unit in Educational Statistics Yearbook of China (中国教育统计年鉴), the data of middle schools between 2011 and 2016 included general middle schools and vocational middle schools. However, we do not consider the data of vocational middle schools, because they range from 54 to 26 , which have litter effect on the whole data.

${ }^{9}$ If we regard the total decreasing number as the measurement standard, the difference between the decline in the number of middle schools and the decline in the number of students enrolled in middle schools is $-19.12 \%(25.55 \%-44.67 \%)$. If we consider that schools are not mobile unlike students, the difference between the above two is $81.84 \%(122.54 \%-40.7 \%)$. 
Table 1.3 The variation in the number of middle schools in counties from 2000 to 2016 (Unit: 10,000 schools)

\begin{tabular}{l|l|l|l}
\hline Year & Town & Village & Total \\
\hline 2000 & 1.47 & 3.93 & 5.40 \\
\hline 2001 & 1.80 & 3.87 & 5.67 \\
\hline 2002 & 1.84 & 3.74 & 5.59 \\
\hline 2003 & 1.75 & 3.73 & 5.47 \\
\hline 2004 & 1.62 & 3.81 & 5.43 \\
\hline 2005 & 1.73 & 3.64 & 5.37 \\
\hline 2007 & 1.81 & 3.53 & 5.34 \\
\hline 2008 & 1.87 & 3.29 & 5.15 \\
\hline 2009 & 1.87 & 3.15 & 5.01 \\
\hline 2010 & 1.87 & 3.02 & 4.89 \\
\hline 2012 & 1.89 & 2.87 & 4.76 \\
\hline 2013 & 2.24 & 2.10 & 4.34 \\
\hline 2014 & 2.29 & 1.94 & 4.23 \\
\hline 2015 & 2.32 & 1.85 & 4.17 \\
\hline 2016 & 2.34 & 1.77 & 4.11 \\
\hline
\end{tabular}

Data Source: The Department of Development, and Planning, Ministry of Education (20012017). Zhongguo jiaoyu tongji nianjian (2000-2016) [Educational Statistics Yearbook of China (2000-2016)], Beijing: People's Education Press

Note: Town includes the town and the county town

number of students enrolled in middle schools in the county nationwide declined from $51,330,100$ in 2000 to $28,399,500$ in 2016, decreasing by 22,930,600 (about $44.67 \%$ of the figure in 2000). The number of students enrolled in middle schools in towns rose from $17,045,400$ in 2000 to $21,729,100$ in 2016, increasing by 4,683,700 (approximately $27.48 \%$ of the figure in 2000). With regard to the villages, the number of students enrolled in rural middle schools decreased by 27,614,300 (about $80.54 \%$ of the figure in 2000), from 34,284,700 in 2000 to 6,670,400 in 2016 (see Table 1.4). In fact, the added students enrolled in rural middle schools transferred to middle schools in towns.

\subsubsection{The Synchronous Expansion of the Scale of Schools and Classes and the Problem of Large-Size Schools and Classes in Towns}

The average size of primary schools (including small-scale schools) in the county rose from 161.32 in 2000 to 268.10 in 2016, increasing by 106.78 (approximately $66.19 \%$ in 2000). In fact, the average size of primary schools in towns grew more remarkably than that of village primary schools (see Fig. 1.1). More specifically, the 
Table 1.4 The number of students enrolled in middle schools between 2000 and 2016 (Unit: 10,000 people)

\begin{tabular}{l|l|l|l}
\hline Year & Town & Village & Total \\
\hline 2000 & 1704.54 & 3428.47 & 5133.01 \\
\hline 2001 & 2245.62 & 3121.30 & 5366.92 \\
\hline 2002 & 2377.20 & 3108.83 & 5486.03 \\
\hline 2003 & 2314.08 & 3160.40 & 5474.48 \\
\hline 2004 & 2187.05 & 3168.27 & 5355.31 \\
\hline 2006 & 2351.33 & 2784.66 & 5135.99 \\
\hline 2007 & 2423.62 & 2563.66 & 4987.28 \\
\hline 2008 & 2430.00 & 2243.32 & 4673.31 \\
\hline 2009 & 2442.85 & 2064.24 & 4507.09 \\
\hline 2010 & 2440.08 & 1934.51 & 4374.59 \\
\hline 2012 & 2432.42 & 1784.47 & 4216.89 \\
\hline 2013 & 2467.42 & 1162.98 & 3630.40 \\
\hline 2014 & 2347.94 & 974.10 & 3322.04 \\
\hline 2015 & 2195.57 & 814.53 & 3010.10 \\
\hline 2016 & 2167.48 & 748.46 & 2915.94 \\
\hline
\end{tabular}

Data Source: The Department of Development, and Planning, Ministry of Education (20012017). Zhongguo jiaoyu tongji nianjian (2000-2016) [Educational Statistics Yearbook of China (2000-2016)], Beijing: People's Education Press

Note: Town includes the town and the county town

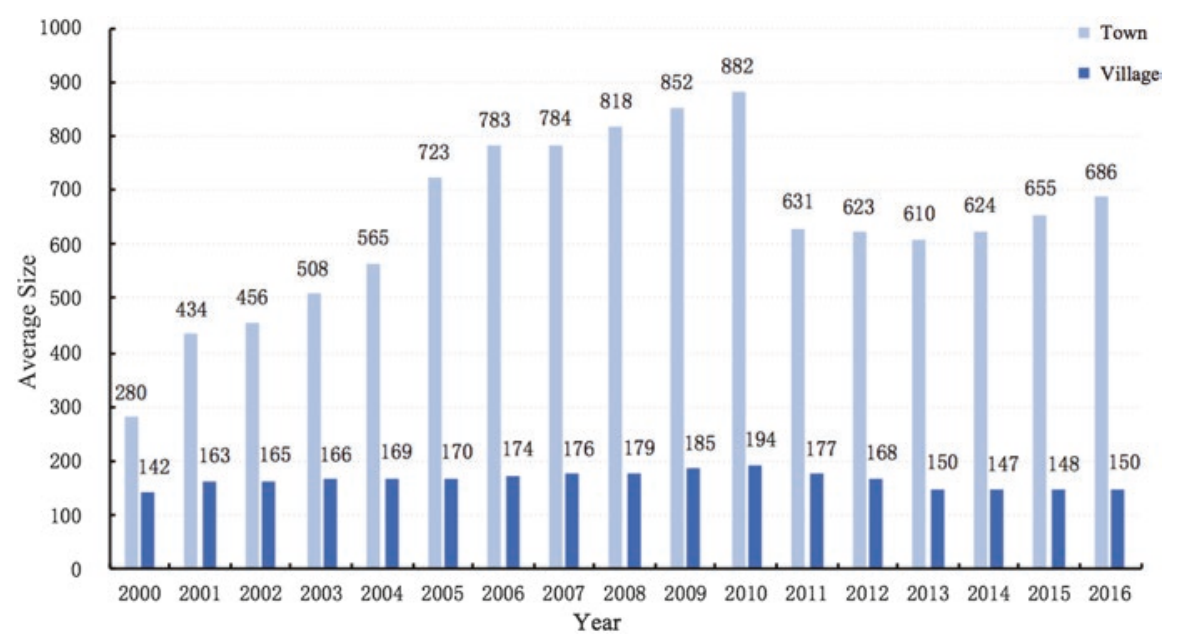

Fig. 1.1 The variation in the average size of primary schools in towns (including towns and county towns) and villages between 2000 and 2016 (Unit: people) 
average size of primary schools in towns rose dramatically from 279.72 in 2000 to 882.03 in 2010 and declined moderately to 686.47 in 2016, increasing by 406.75 in the past 16 years. In contrast, the average size of village primary schools (including small-scale schools) rose from 142.25 in 2000 to 149.67 in 2016, increasing slightly by 7.42 in the past 16 years (see Table 1.5). Although the absolute value of the average size of primary schools in towns and villages cannot exceed that of the cities, the variation rate of the average size of primary schools in towns $(140.01 \%)$ and villages (145.41\%) is higher than that of the cities (5.22\%), and the figure in towns is the highest. After analyzing the development trend of the primary school consolidation in the county, we can find that concentrating on the benefits of size (or scale) is the basic value in the whole process.

With regard to the middle schools, the relevant figure increased first and then decreased, but it exhibited a decreasing trend in the whole process. The average size of middle schools in counties was 950.72 in 2000, rising to the highest (1000.42) in 2003 and then dropping to 706.56 in 2016. The figure declined by 244.16 (approximately $25.68 \%$ of the figure in 2000) in the past 16 years (see Fig. 1.2). From

Table 1.5 The variation in the average size of primary schools in towns, villages, and cities between 2000 and 2016 (Unit: people)

\begin{tabular}{l|l|l|l|l|l}
\hline Year & Total & City & Town & Village & County \\
\hline 2000 & 177.85 & 483.06 & 279.72 & 142.25 & 161.32 \\
\hline 2001 & 207.11 & 621.65 & 434.18 & 163.40 & 187.73 \\
\hline 2002 & 213.55 & 645.17 & 455.76 & 165.40 & 192.33 \\
\hline 2003 & 219.93 & 687.88 & 507.55 & 166.42 & 195.59 \\
\hline 2004 & 226.88 & 756.28 & 564.66 & 169.46 & 199.69 \\
\hline 2005 & 235.81 & 832.39 & 722.84 & 169.59 & 207.62 \\
\hline 2006 & 248.57 & 929.87 & 783.47 & 174.47 & 220.17 \\
\hline 2007 & 260.81 & 988.93 & 784.25 & 176.22 & 227.32 \\
\hline 2008 & 271.92 & 1027.03 & 817.98 & 179.24 & 235.31 \\
\hline 2009 & 285.58 & 1071.61 & 851.88 & 185.36 & 246.76 \\
\hline 2010 & 306.48 & 1096.34 & 882.03 & 193.61 & 263.86 \\
\hline 2011 & 321.58 & 963.86 & 630.58 & 176.73 & 259.90 \\
\hline 2012 & 324.95 & 997.27 & 622.78 & 167.89 & 258.18 \\
\hline 2013 & 315.92 & 1019.47 & 610.45 & 150.41 & 244.80 \\
\hline 2014 & 325.51 & 1063.47 & 624.18 & 147.15 & 247.76 \\
\hline 2015 & 341.80 & 1113.48 & 655.30 & 148.15 & 258.66 \\
\hline 2016 & 359.08 & 1159.40 & 686.47 & 149.67 & 268.10 \\
\hline $\begin{array}{l}\text { The increasing average size of primary } \\
\text { schools from 2000 to 2016 }\end{array}$ & 181.23 & 676.34 & 406.75 & 7.42 & 106.78 \\
\hline The growth rate from 2000 to 2016 & $101.90 \%$ & $140.01 \%$ & $145.41 \%$ & $5.22 \%$ & $66.19 \%$ \\
\hline
\end{tabular}

Data Source: The Department of Development, and Planning, Ministry of Education (20012017). Zhongguo jiaoyu tongji nianjian (2000-2016) [Educational Statistics Yearbook of China (2000-2016)], Beijing: People's Education Press

Note: Town includes the town and the county town. County includes the town (including the town and the county town) and the village 


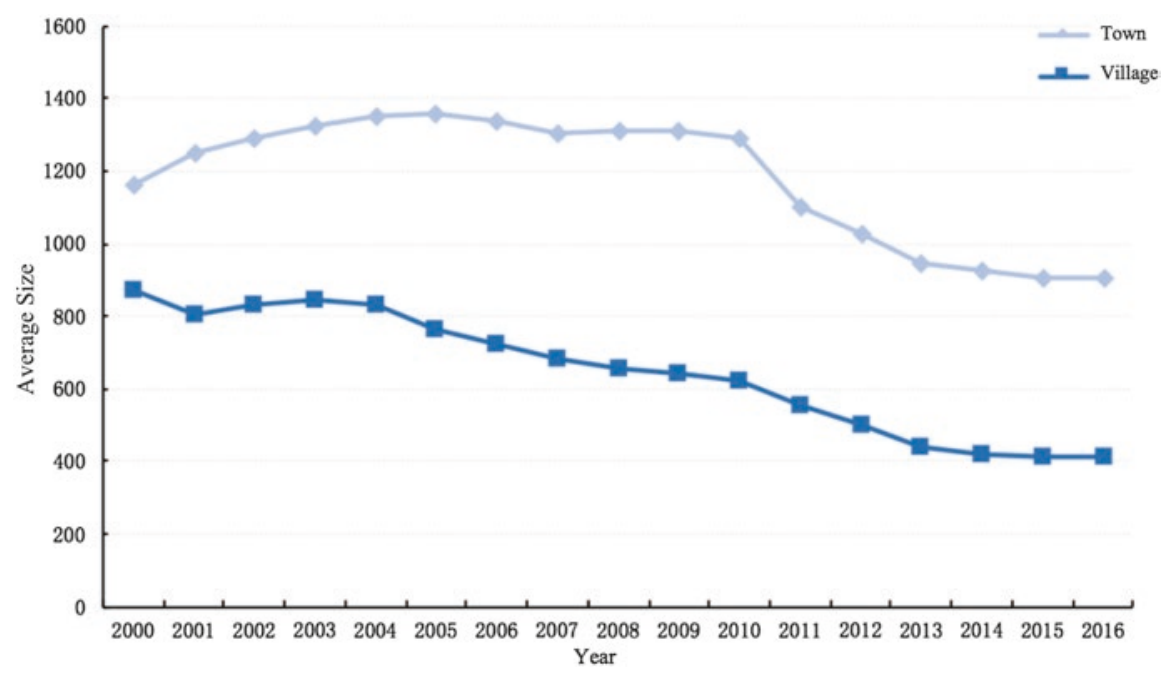

Fig. 1.2 The variation in the average size of middle schools in towns and villages

Fig. 1.2, we can find that the average size of middle schools in villages declined more significantly than the figure in towns. More specifically, the value for towns rose from 1161.29 in 2000 to 1357.34 in 2005 and then dropped to 904.51 in 2016, decreasing by 256.78 (approximately $22.11 \%$ of the figure in 2000). By contrast, the average size of middle schools in villages declined from 872.09 in 2000 to 412.49 in 2016, decreasing by 459.60 (about $52.79 \%$ of the figure in 2000) (see Table 1.6). Compared to the cities' situation, the average size of middle schools in towns and villages was lower than for the figure of cities in 2016, but between 2001 and 2006, the figure showed an adverse trend. For example, in 2005, the average size of middle schools in towns was highest and exceeded that of the figure in cities. The difference between them was nearly 87.49. If we consider the huge difference between the sizes of middle schools in towns, some middle schools in towns may actually have a huge size, and there may be some "superlarge middle schools" to which governments should pay attention.

The average class size in primary schools (including small-scale schools) in counties rose from 32.66 in 2000 to 36.34 in 2010 and fell to 34.71 in 2016, only increasing by 2.05 in the past 16 years. However, if we separate the figure for primary schools in towns from the figure in villages, we can find that the figure in villages declined slightly from around 31 (between 2000 and 2011) to 27.60 in 2016. In contrast, the figure in towns underwent a rapid expansion and then a narrow trend. For example, the figure in towns rose from 39.44 in 2000 to 48.88 in 2010, increasing by 9.44 (approximately $23.94 \%$ of the figure in 2000) in the 10 years and then dropping to 43.29 in 2016 . It is worth mentioning that the figure in towns exceeded the national standards of class size (45 students in every class on average) from 2004 to 2011 and that it was also higher than the figure in cities from 2005 to 2010 (see Table 1.7). If we define "56-65 students in every class on aver- 
Table 1.6 The variation in the average size of middle schools in cities, towns, and villages between 2000 and 2016 (Unit: people)

\begin{tabular}{l|l|l|l|l|l}
\hline Year & Total & City & Town & Village & County \\
\hline 2000 & 983.61 & 1187.46 & 1161.29 & 872.09 & 950.72 \\
\hline 2001 & 981.47 & 1207.60 & 1248.47 & 806.00 & 946.33 \\
\hline 2002 & 1021.34 & 1270.20 & 1289.43 & 830.73 & 982.12 \\
\hline 2003 & 1038.82 & 1272.60 & 1324.53 & 848.41 & 1000.42 \\
\hline 2004 & 1026.80 & 1280.08 & 1348.53 & 831.67 & 986.01 \\
\hline 2005 & 997.30 & 1269.85 & 1357.34 & 764.91 & 955.92 \\
\hline 2006 & 980.57 & 1321.42 & 1340.72 & 726.60 & 934.65 \\
\hline 2007 & 967.86 & 1379.49 & 1302.95 & 682.59 & 907.18 \\
\hline 2008 & 966.04 & 1407.55 & 1309.00 & 656.19 & 899.26 \\
\hline 2009 & 967.41 & 1443.64 & 1308.14 & 641.03 & 895.86 \\
\hline 2010 & 962.35 & 1454.90 & 1288.77 & 622.42 & 886.94 \\
\hline 2011 & 936.27 & 1335.19 & 1103.40 & 553.88 & 837.29 \\
\hline 2012 & 895.04 & 1318.17 & 1026.38 & 501.91 & 785.65 \\
\hline 2013 & 840.87 & 1285.53 & 946.57 & 440.65 & 722.19 \\
\hline 2014 & 833.22 & 1278.57 & 925.12 & 422.69 & 708.85 \\
\hline 2015 & 822.81 & 1253.16 & 906.73 & 413.45 & 701.84 \\
\hline 2016 & 830.69 & 1249.09 & 904.51 & 412.49 & 706.56 \\
\hline $\begin{array}{l}\text { The increasing average size of middle } \\
\text { schools from 2000 to 2016 }\end{array}$ & -152.92 & 61.63 & -256.78 & -459.60 & -244.16 \\
\hline The growth rate from 2000 to 2016 & $-15.55 \%$ & $5.19 \%$ & $-22.11 \%$ & $-52.70 \%$ & $-25.68 \%$ \\
\hline Dat Sourc: The Depe & & & & & \\
\hline
\end{tabular}

Data Source: The Department of Development, and Planning, Ministry of Education (20012017). Zhongguo jiaoyu tongji nianjian (2000-2016) [Educational Statistics Yearbook of China (2000-2016)], Beijing: People's Education Press

Note: Town includes the town and the county town. County includes the town (including the town and the county town) and the village

age” as “large class size”(大班额) and “over 66 students in every class on average” as “giant class size”(超大班额), we can calculate that the proportion of "large class size" in primary schools in towns increased from $22.16 \%$ in $2001^{10}$ to $32.39 \%$ in 2006 and then dropped to $15.96 \%$ in 2016 due to the improvement on relevant issues. Moreover, the proportion of "giant class size" in primary schools in towns rose from $9.50 \%$ in 2001 to $14.66 \%$ in 2006 and then declined to $5.57 \%$ in 2016 , decreasing by $3.93 \%$ from 2001 to 2016 (see Table 1.8). It is quite interesting that the proportion of large class size or giant class size declined from 2001 to 2016, which also indicated outcomes of some policies aiming at controlling class size.

\footnotetext{
${ }^{10}$ The statistic index of class size of primary schools in the Educational Statistics Yearbook of China (2000) is different from it in the Educational Statistics Yearbook of China (2001-2016). In terms of class size, the data of "over 50 students in every class on average" is available and not the data of "56-65 students in every class on average" and the data of "over 66 students in every class on average" in the Educational Statistics Yearbook of China (2000). Thus, in this part, the author uses the data of 2001, instead of the data of 2000 .
} 
Table 1.7 The variation in the class size of primary schools in cities, towns, and villages between 2000 and 2016 (Unit: people)

\begin{tabular}{l|l|l|l|l|l}
\hline Year & Total & City & Town & Village & County \\
\hline 2000 & 33.93 & 44.60 & 39.44 & 30.97 & 32.66 \\
\hline 2001 & 33.84 & 42.14 & 41.54 & 31.13 & 32.84 \\
\hline 2002 & 34.48 & 43.63 & 43.15 & 31.31 & 33.32 \\
\hline 2003 & 34.75 & 44.68 & 43.74 & 31.28 & 33.39 \\
\hline 2004 & 35.11 & 45.69 & 45.10 & 31.39 & 33.60 \\
\hline 2005 & 35.48 & 46.29 & 47.29 & 31.21 & 33.97 \\
\hline 2006 & 36.29 & 46.91 & 48.64 & 31.64 & 34.90 \\
\hline 2007 & 36.78 & 47.71 & 48.68 & 31.59 & 35.17 \\
\hline 2008 & 37.12 & 47.74 & 48.81 & 31.64 & 35.45 \\
\hline 2009 & 37.39 & 47.54 & 48.66 & 31.82 & 35.75 \\
\hline 2010 & 37.99 & 47.70 & 48.88 & 32.08 & 36.34 \\
\hline 2011 & 38.49 & 47.09 & 45.63 & 30.98 & 36.14 \\
\hline 2012 & 37.78 & 46.45 & 44.61 & 29.56 & 35.25 \\
\hline 2013 & 37.46 & 46.53 & 44.09 & 28.25 & 34.61 \\
\hline 2014 & 37.42 & 46.23 & 43.65 & 27.81 & 34.45 \\
\hline 2015 & 37.72 & 46.22 & 43.71 & 27.74 & 34.75 \\
\hline 2016 & 37.71 & 45.77 & 43.29 & 27.60 & 34.71 \\
\hline $\begin{array}{l}\text { The increasing average size of primary schools } \\
\text { from 2000 to 2016 }\end{array}$ & 3.78 & 1.17 & 3.85 & -3.37 & 2.05 \\
\hline The growth rate from 2000 to 2016 & $11.14 \%$ & $2.62 \%$ & $9.76 \%$ & $-10.88 \%$ & $6.28 \%$ \\
\hline
\end{tabular}

Data Source: The Department of Development, and Planning, Ministry of Education (20012017). Zhongguo jiaoyu tongji nianjian (2000-2016) [Educational Statistics Yearbook of China (2000-2016)], Beijing: People's Education Press

Note: Town includes the town and the county town. County includes the town (including the town and the county town) and the village

The problem of large class size in middle schools is worse than that of primary schools. Between 2001 and 2008, the proportion of large class size in middle schools in towns was over $50 \%$, and the figure for giant class size was over $23 \%$ as well. It is gratifying that since 2010 , the proportion of large and giant class size in middle schools in counties has decreased significantly. By 2016, the proportion of large class size in middle schools in towns and villages had dropped to $20.94 \%$ and $12.97 \%$, respectively, decreasing by $23.55 \%$ and $32.63 \%$, respectively, compared to the figure in 2000. However, the figure in towns was always higher than the figure in cities. The figure in villages had been lower than the figure in cities since 2010 . In fact, the average class size of middle schools in counties was higher than the national standard (50 students in every class on average) from 2001 to 2012. Thus, the large class size of middle schools in counties was a serious problem for the process of rural school consolidation, particularly in towns (Tables 1.9 and 1.10). 
Table 1.8 The variation in the proportion of "large class size" and "giant class size" in primary schools in cities, towns, and villages between 2001 and 2016 (\%)

\begin{tabular}{l|l|l|l|l|l|l}
\hline \multirow{2}{*}{$\begin{array}{l}\text { Year } \\
\text { Yrimary schools }\end{array}$} & \multicolumn{3}{l|l}{$\begin{array}{l}\text { The proportion of "giant class size" in } \\
\text { primary schools }\end{array}$} \\
\hline 2001 & 24.60 & Town & Village & City & Town & Village \\
\hline 2002 & 23.08 & 22.16 & 6.30 & 9.67 & 9.50 & 1.85 \\
\hline 2003 & 23.49 & 22.35 & 6.52 & 8.70 & 9.15 & 1.97 \\
\hline 2004 & 25.45 & 23.39 & 6.68 & 8.37 & 9.51 & 2.04 \\
\hline 2005 & 26.22 & 26.29 & 6.98 & 8.90 & 11.25 & 2.14 \\
\hline 2006 & 27.00 & 29.73 & 7.11 & 9.18 & 12.89 & 2.22 \\
\hline 2007 & 27.82 & 32.39 & 7.51 & 9.49 & 14.66 & 2.39 \\
\hline 2008 & 27.11 & 31.54 & 7.21 & 10.08 & 14.19 & 2.29 \\
\hline 2009 & 26.20 & 30.85 & 7.02 & 10.01 & 13.84 & 2.21 \\
\hline 2010 & 25.81 & 29.92 & 6.90 & 9.52 & 13.18 & 2.10 \\
\hline 2011 & 24.39 & 29.65 & 6.93 & 9.18 & 12.90 & 2.02 \\
\hline 2012 & 22.47 & 24.16 & 6.10 & 8.89 & 10.09 & 1.82 \\
\hline 2013 & 21.20 & 21.81 & 5.21 & 7.81 & 9.02 & 1.47 \\
\hline 2014 & 19.14 & 20.54 & 4.20 & 7.39 & 8.71 & 1.15 \\
\hline 2015 & 18.43 & 18.41 & 3.67 & 6.47 & 7.70 & 0.95 \\
\hline 2016 & 16.50 & 17.86 & 3.56 & 6.03 & 7.33 & 0.91 \\
\hline
\end{tabular}

Data Source: The Department of Development, and Planning, Ministry of Education (20012017). Zhongguo jiaoyu tongji nianjian (2000-2016) [Educational Statistics Yearbook of China (2000-2016)], Beijing: People's Education Press. The data in the above table are the result of calculation

Note: Town includes the town and the county town

\subsubsection{The Negative Impact of Educational Urbanization}

With reference to the concept of urbanization, educational urbanization in this chapter is characterized as a ratio between students in urban schools (including city schools and town schools or excepting countryside schools) and total students. ${ }^{11}$

The urbanization rate of primary schools in China increased from $12.71 \%$ in 1980 to $21.61 \%$ in 1990 and reached $34.65 \%$ in 2000 and $46.18 \%$ in 2010. From 2000 to 2010 , the figure increased by $11.53 \%$, but it was nevertheless slightly below the increasing rate of urbanization nationwide (approximately 13.73\%). Since 2010, educational urbanization developed rapidly. By 2016, the urbanization rate of primary schools in China rose to $70.83 \%$, increasing by $24.65 \%$ from 2010 to 2016 . It

\footnotetext{
${ }^{11}$ The rate of educational urbanization $=($ students in cities + student in towns $) /$ total students (including students in cities, towns, and the countryside). The rate of educational urbanization can be calculated by classifying different educational stages. Generally, if the educational stages are higher, the rate of educational urbanization is higher. For example, higher education institutions or universities are mainly distributed in urban areas. To some degrees, the urbanization rate of primary schools may reflect the disappearance of rural schools.
} 
Table 1.9 The variation in the average class size of middle schools in cities, towns, and villages between 2000 and 2016 (Unit people)

\begin{tabular}{l|l|l|l|l|l}
\hline Year & Total & City & Town & Village & County \\
\hline 2000 & 46.44 & 35.93 & 41.59 & 54.39 & 49.35 \\
\hline 2001 & 55.74 & 50.40 & 57.45 & 56.57 & 56.93 \\
\hline 2002 & 56.68 & 51.55 & 58.01 & 57.74 & 57.86 \\
\hline 2003 & 56.81 & 51.31 & 58.25 & 58.01 & 58.11 \\
\hline 2004 & 56.60 & 51.11 & 57.92 & 57.88 & 57.90 \\
\hline 2005 & 55.93 & 50.73 & 58.14 & 56.26 & 57.11 \\
\hline 2006 & 55.73 & 50.42 & 58.04 & 55.80 & 56.87 \\
\hline 2007 & 55.17 & 51.28 & 57.69 & 54.52 & 56.12 \\
\hline 2008 & 54.61 & 51.27 & 57.26 & 53.49 & 55.47 \\
\hline 2009 & 53.80 & 51.00 & 56.35 & 52.39 & 54.53 \\
\hline 2010 & 52.90 & 50.54 & 55.27 & 51.33 & 53.53 \\
\hline 2011 & 51.83 & 50.27 & 53.70 & 50.04 & 52.47 \\
\hline 2012 & 50.27 & 49.52 & 51.77 & 47.99 & 50.60 \\
\hline 2013 & 48.82 & 48.65 & 50.17 & 45.77 & 48.90 \\
\hline 2014 & 48.30 & 48.06 & 49.65 & 45.20 & 48.43 \\
\hline 2015 & 47.72 & 47.17 & 49.20 & 44.65 & 48.00 \\
\hline 2016 & 47.30 & 46.76 & 48.73 & 44.22 & 47.59 \\
\hline $\begin{array}{l}\text { The increasing average size of class in middle } \\
\text { schools from 2000 to 2016 }\end{array}$ & 0.86 & 10.83 & 7.14 & -10.17 & -1.76 \\
\hline The growth rate from 2000 to 2016 & $1.85 \%$ & $30.14 \%$ & $17.17 \%$ & $-18.70 \%$ & $-3.57 \%$ \\
\hline
\end{tabular}

Data Source: The Department of Development, and Planning, Ministry of Education (20012017). Zhongguo jiaoyu tongji nianjian (2000-2016) [Educational Statistics Yearbook of China (2000-2016)], Beijing: People's Education Press. The data in the above table are the result of calculation

surpassed the urbanization rate that increased by $7.40 \%$ in the same period. Compared with the urbanization rate of primary schools, the urbanization rate of middle schools increased more rapidly. In 1980, the urbanization rate of middle schools was only $22.47 \%$; it reached $33.67 \%$ in $1990,44.41 \%$ in 2000 , and $66.18 \%$ in 2010 and rose considerably to $84.59 \%$ in 2016 . The urbanization rate of middle schools was growing at a rate of about $1 \%$ per year from 1980 to 2000 and about $2 \%$ per year from 2000 to 2010 , increasing by $21.77 \%$ from 2000 to 2010 . The figure increased dramatically by $18.41 \%$ from 2010 to 2016 (see Table 1.11). Overall, from 2000 to 2016, the urbanization rate of primary schools and middle schools increased by $36.18 \%$ and $40.18 \%$, respectively, and it was higher than the urbanization rate of China that increased by $21.33 \%$ (from $36.22 \%$ in 2000 to $57.35 \%$ in 2016).

However, a growing number of rural schools disappeared in the process of urbanization and educational urbanization. In 1985, the ratio between the number of villages and primary schools was $1.24: 1,{ }^{12}$ which meant that every village had a

\footnotetext{
${ }^{12}$ The ratio between the number of villages and primary schools $=$ the number of administrative
} 
Table 1.10 The variation in the proportion of large and giant class size of middle schools in cities, towns, and villages between 2000 and 2016 (\%)

\begin{tabular}{|c|c|c|c|c|c|c|}
\hline \multirow[b]{2}{*}{ Year } & \multicolumn{3}{|c|}{$\begin{array}{l}\text { The proportion of large class size in } \\
\text { middle schools }\end{array}$} & \multicolumn{3}{|c|}{$\begin{array}{l}\text { The proportion of giant class size in } \\
\text { middle schools }\end{array}$} \\
\hline & City & Town & Village & City & Town & Village \\
\hline 2000 & 35.48 & 44.49 & 45.60 & 12.03 & 16.16 & 17.13 \\
\hline 2001 & 38.73 & 52.92 & 49.00 & 15.82 & 23.99 & 21.42 \\
\hline 2002 & 38.59 & 56.14 & 52.05 & 15.30 & 27.44 & 23.61 \\
\hline 2003 & 38.42 & 56.56 & 53.81 & 15.27 & 26.90 & 25.79 \\
\hline 2004 & 37.39 & 55.12 & 52.01 & 13.58 & 26.40 & 24.39 \\
\hline 2005 & 34.31 & 54.01 & 48.80 & 11.80 & 25.69 & 22.42 \\
\hline 2006 & 33.59 & 53.29 & 45.84 & 11.39 & 26.22 & 20.47 \\
\hline 2007 & 35.09 & 51.99 & 42.18 & 12.53 & 24.73 & 17.86 \\
\hline 2008 & 34.37 & 50.17 & 38.68 & 12.34 & 23.79 & 16.03 \\
\hline 2009 & 33.15 & 46.79 & 35.10 & 11.85 & 21.67 & 13.70 \\
\hline 2010 & 31.02 & 43.13 & 31.65 & 10.96 & 18.92 & 11.81 \\
\hline 2011 & 29.85 & 37.86 & 27.77 & 10.75 & 15.75 & 9.96 \\
\hline 2012 & 27.15 & 31.49 & 22.79 & 9.28 & 12.80 & 8.05 \\
\hline 2013 & 23.75 & 27.61 & 18.73 & 8.09 & 11.23 & 6.84 \\
\hline 2014 & 20.93 & 24.37 & 16.11 & 6.54 & 9.73 & 5.50 \\
\hline 2015 & 17.82 & 23.18 & 14.57 & 5.21 & 8.75 & 4.86 \\
\hline 2016 & 15.55 & 20.94 & 12.97 & 4.12 & 7.16 & 3.90 \\
\hline
\end{tabular}

Data Source: The Department of Development, and Planning, Ministry of Education (20012017). Zhongguo jiaoyu tongji nianjian (2000-2016) [Educational Statistics Yearbook of China (2000-2016)], Beijing: People's Education Press. The data in the above table are the result of calculation

Note: Town includes the town and the county town

primary school. In 2000 , the ratio rose to $1.66: 1$, which meant that around 1.5 villages had a primary school. In 2016, the ratio rose again to 5.26:1, which meant that around five villages could have a primary school (see Table 1.12). Many villages' primary schools had disappeared. Many villages' primary schools being shut down coincided with the merge reform of villages and towns. The number of administrative villages declined from 731,700 in 2000 to 559,200 in 2016 , decreasing by 172,500 (approximately $23.57 \%$ of the value for 2000). The ratio ${ }^{13}$ between the number of villages and small-scale schools rose from 4.64:1 in 2000 to 9.67:1 in 2001 but declined to 6.44:1 in 2016, which implies that approximately seven villages had one primary school on average (see Table 1.12).

villages/the number of primary schools in administrative villages. In China, most rural dwellers live in administrative villages, and the ratio between villages and primary schools can represent the distance that students travel to school. In other words, if the ratio is higher, the distance that students travel to school is longer.

${ }^{13}$ The ratio between the number of villages and small-scale schools $=$ the number of administrative villages/the number of small-scale schools in administrative villages. The ratio also can be regarded as a variable to represent the distance that students travel to school. 
Table 1.11 The urbanization rate of primary schools and middle schools in China (\%)

\begin{tabular}{|c|c|c|c|}
\hline Year & $\begin{array}{l}\text { Urbanization } \\
\text { rate }\end{array}$ & $\begin{array}{l}\text { Urbanization rate of } \\
\text { primary schools }\end{array}$ & $\begin{array}{l}\text { Urbanization rate of } \\
\text { middle schools }\end{array}$ \\
\hline 2000 & 36.22 & 34.65 & 44.41 \\
\hline 2001 & 37.66 & 31.40 & 51.47 \\
\hline 2002 & 39.09 & 33.03 & 52.93 \\
\hline 2003 & 40.53 & 34.22 & 52.25 \\
\hline 2004 & 41.76 & 34.39 & 51.07 \\
\hline 2005 & 42.99 & 36.05 & 54.88 \\
\hline 2006 & 44.34 & 37.67 & 56.82 \\
\hline 2007 & 45.89 & 40.83 & 60.79 \\
\hline 2008 & 46.99 & 42.65 & 62.97 \\
\hline 2009 & 48.34 & 43.85 & 64.40 \\
\hline 2010 & 49.95 & 46.18 & 66.18 \\
\hline 2011 & 51.27 & 59.05 & 77.05 \\
\hline 2012 & 52.57 & 62.33 & 79.55 \\
\hline 2013 & 53.73 & 65.63 & 81.66 \\
\hline 2014 & 54.77 & 67.73 & 82.93 \\
\hline 2015 & 56.10 & 69.40 & 83.71 \\
\hline 2016 & 57.35 & 70.83 & 84.59 \\
\hline $\begin{array}{l}\text { The growth rate from } \\
2000 \text { to } 2010\end{array}$ & 13.73 & 11.53 & 21.77 \\
\hline $\begin{array}{l}\text { The growth rate from } \\
2010 \text { to } 2016\end{array}$ & 7.40 & 24.65 & 18.41 \\
\hline
\end{tabular}

Data Source: National Bureau of Statistics of China (2017). Zhongguo tongji nianjian (2017) [Statistics Yearbook of China (2017)], Beijing: China Statistics Press. The Department of Development, and Planning, Ministry of Education (2001-2017). Zhongguo jiaoyu tongji nianjian (2000-2016) [Educational Statistics Yearbook of China (2000-2016)], Beijing: People's Education Press. The data of the urbanization rate of primary schools and middle schools in the above table are the results of calculation

As a result of the educational urbanization and the disappearance of rural schools, the distance that students travel to schools has become longer, and many young students have to live in boarding schools. According to a research report (Pang 2006), among 1200 students in primary schools surveyed from 3 counties and 15 towns, nearly $40 \%$ have to travel $5 \mathrm{~km}$ daily to school and nearly $10 \%$ over $10 \mathrm{~km}$. Another internal survey covering 8 counties and 77 towns or villages, which was conducted by the China Institute of Rural Education Development in Northeast Normal University, also revealed that students who experienced rural school consolidation have to travel an extra $4.05 \mathrm{~km}$ to school on average.

In order to save time and economic cost of students in the countryside where the traffic conditions are poor and the distance between the school and students' homes is far, many local governments mandate students to enroll in boarding schools. At a country level, the total number of students in primary boarding schools in the county was 6.7 million in 2006 (about $7.36 \%$ of the students in primary school), while in 2016 , the figure rose to $9,425,200$ (nearly $14.18 \%$ of the students in primary school). 
Table 1.12 The number of primary schools, small-scale schools, and administrative villages between 2000 and 2016

\begin{tabular}{|l|l|l|l|l|l|l}
\hline Year & $\begin{array}{l}\text { The number of } \\
\text { primary schools }\end{array}$ & $\begin{array}{l}\text { The number of } \\
\text { small-scale schools }\end{array}$ & $\begin{array}{l}\text { The number of } \\
\text { administrative villages }\end{array}$ & $\begin{array}{l}\text { Ratio } \\
\text { I* }\end{array}$ & $\begin{array}{l}\text { Ratio } \\
\text { II }\end{array}$ & $\begin{array}{l}\text { Ratio } \\
\text { III }\end{array}$ \\
\hline 2000 & 440,284 & 157,519 & 731,659 & 1.66 & 4.64 & 1.66 \\
\hline 2001 & 416,198 & 110,419 & 699,974 & 1.68 & 6.34 & 1.76 \\
\hline 2002 & 384,004 & 108,250 & 681,277 & 1.77 & 6.29 & 1.91 \\
\hline 2003 & 360,366 & 101,674 & 663,486 & 1.84 & 6.53 & 2.03 \\
\hline 2004 & 337,318 & 98,096 & 644,166 & 1.91 & 6.57 & 2.17 \\
\hline 2005 & 316,791 & 92,894 & 629,079 & 1.99 & 6.77 & 2.31 \\
\hline 2006 & 295,052 & 87,590 & 623,669 & 2.11 & 7.12 & 2.48 \\
\hline 2007 & 271,584 & 83,118 & 612,709 & 2.26 & 7.37 & 2.69 \\
\hline 2008 & 253,041 & 77,519 & 604,285 & 2.39 & 7.80 & 2.89 \\
\hline 2009 & 234,157 & 70,954 & 599,078 & 2.56 & 8.44 & 3.12 \\
\hline 2010 & 210,894 & 65,447 & 594,658 & 2.82 & 9.09 & 3.47 \\
\hline 2011 & 169,045 & 60,972 & 589,653 & 3.49 & 9.67 & 4.33 \\
\hline 2012 & 155,008 & 62,544 & 588,475 & 3.80 & 9.41 & 4.72 \\
\hline 2013 & 140,328 & 73,555 & 588,547 & 4.19 & 8.00 & 5.21 \\
\hline 2014 & 128,703 & 78,565 & 585,451 & 4.55 & 7.45 & 5.68 \\
\hline 2015 & 118,381 & 81,818 & 580,856 & 4.91 & 7.10 & 6.18 \\
\hline 2016 & 106,403 & 86,800 & 559,186 & 5.26 & 6.44 & 6.88 \\
\hline
\end{tabular}

Data Source: The Department of Development, and Planning, Ministry of Education (20012017). Zhongguo jiaoyu tongji nianjian (2000-2016) [Educational Statistics Yearbook of China (2000-2016)], Beijing: People's Education Press. National Bureau of Statistics of China (20012017). Zhongguo tongji nianjian (2001-2017) [Statistics Yearbook of China (2001-2017)], Beijing: China Statistics Press. The data of the urbanization rate of primary schools and middle schools in the above table are the result of calculation

Note: "Ratio I" refers to the ratio between the number of villages and primary schools. "Ratio II" refers to the ratio between the number of villages and small-scale schools. "Ratio III" refers to the ratio between the number of villages in 2000 and primary schools between 2000 and 2016

In the counties located in the eastern, central, and western parts of China, the percentage of boarding students in primary schools was $6.93 \%, 15.11 \%$, and $20.53 \%$, respectively. ${ }^{14} \mathrm{~A}$ research by the China Institute of Rural Education Development in Northeast Normal University in 2008 on 870 boarding students in primary schools found that $55.5 \%$ of them became boarding students before Grade 3. Thus, the problem of young students in boarding primary schools is serious.

\footnotetext{
${ }^{14}$ The data were derived from the Concise Statistical Analysis of Educational Development in China (2006) and the Concise Statistical Analysis of Educational Development in China (2016), that is, the internal data of the Ministry of Education (PRC).
} 


\subsubsection{A Theoretical Framework for Rural School Consolidation}

The establishment of standards for rural school consolidation is a key policy issue when adjusting rural school layout and promoting scientific, rational, and standardized rural school consolidation. However, current national standards are too ambiguous to prevent the local problematic adjustment. Those standards proposed by scholars are usually too rational and static to guide complex, dynamic rural reality. The standards proposed by the local education bureaus prefer efficiency to the farmers' benefits. The last section of this chapter would like to propose a new framework for establishing the standards by considering all the real constraints.

\subsubsection{Constraints for Rural School Consolidation}

\subsubsection{Physical Constraints}

Physical constraints refer to those existing geographical and traffic conditions affecting school closure and consolidation.

\section{Geographical Conditions}

This refers to the comprehensive factors affecting the geographical conditions of schools, such as topography, climate, geographical structure, and hydrology. Geographical conditions can affect people's choice of residence first and then the distribution and density of population, ultimately affecting the establishment and closure or consolidation of schools. In terms of topography, China has mountains, plateaus, hills, plains, islands, and reservoir areas. Because of the different traffic conditions of different topographies, students may experience different convenience levels with regard to accessing schools. Students living in mountains, hills, islands, or forest areas may spend more time traveling to school; therefore, schools should be distributed widely in those areas. In plateaus, plains, and reservoir areas, schools should be distributed narrowly, which would increase students' convenience in traveling to and from schools.

In terms of the climate, the northern part of China is cold in winter, and the southern part of China is hot in summer. If students walk outside in a cold or hot environment for a long time, they may suffer frost or heat stroke. Therefore, when governments promote school consolidation, they need to implement some policies to ensure that students can go to a school or boarding school that is near them. Similarly, islands or the land near the sea is affected by typhoons, so the distribution of schools needs special standards. In terms of the geological structure, many areas in China are located in earthquake zones. If the school is located in an earthquake 
zone, it should be closed or relocated to other zones less prone to earthquakes. In terms of hydrology, due to the influence of seasonal precipitation, areas near rivers and lakes will suffer floods or levee breakage, so in those areas, schools should be located on high-altitude sites.

\section{Traffic Conditions}

This refers to the degree of convenience and safety of students travelling from their homes to schools. The convenience level of traffic can be affected by four factors, namely, traffic modes, road conditions, topographic features, and traffic distance. In terms of traffic modes, students can travel by walking, riding a bicycle or a motorbike, and taking a bus or a school bus, ship, etc. Because the power base of traffic modes is different, the convenience level of traffic differs as well. In terms of road conditions, there are first-class highways (一级公路), rural highways, rural paths, and rugged mountain roads in the countryside. Different road conditions have a direct impact on students' travelling time. Generally, the more complex the topographic features, the more terrible the dynamic foundation of traffic and road conditions. If road conditions are poor, it will be less convenient for students to go to school. Taking all these factors into account, we can condense those factors as having an effect on the traffic convenience into a variable, namely, traffic time. Long traffic time means not only long traffic distance, inconvenient traffic modes, poor road conditions, and complex terrain features but also the high cost of traffic. If school closure and consolidation place a heavy burden on disadvantaged farmers, the ethical foundation of this reform will become questionable. Traffic safety is related not only to road conditions and topographic features but also to the natural environment. If there are seriously safety hazards such as mudslides, mountain collapse, and embankment bursts, or the threat of wild animals on the students' way to school and back, we need to retain some small-scale schools.

\subsubsection{Social Constraints}

Social constraints refer to the factors affecting the economic and social development in a certain area, such as cultural or traditional customs, the will of the people and government, and other factors. The school is a part of social organization, so different social, political, economic, and cultural characteristics directly restrict the distribution of schools.

\section{Population}

There are two kinds of population variables that can affect rural school consolidation. One is the static distribution of population, demographic structure, and population density. The other is the dynamic change of human fertility level and migration 
intensity. In a certain geographical space, the number and structure of people can directly determine the number of students in the area. Due to low-level urbanization in the county, the population density is low, and people's residences are dispersed, which has a negative influence on running large-scale schools in rural areas. For example, the southeastern part of China has a great amount of population, and the northwestern part of China has a small amount of population. Although the land area of the southeastern part accounts for $43 \%$ of China's land area, the population accounts for $94 \%$ of China's population. In contrast, the land area of the northwestern part accounts for $57 \%$ of China's land area, but the population only accounts for $6 \%$ of China's population. Thus, governments in the northwestern region find it more difficult to promote rural school consolidation. With the decline in birth rate in China, the phenomenon of rural families with one child or no child has become more popular, and it is difficult for a growing number of rural schools to retain student enrollment. Furthermore, with the rapid progress of urbanization, an increasing number of migrant workers take their children to cities, which also makes this problem more serious. However, sometimes, migrant children may also choose to return to rural schools, because the supply of educational resources in cities is limited and they cannot study in cities permanently. In fact, their choice of schools may be affected by the change of some policies, such as the policy of rural education and even some political policies.

\section{Ethnic, Religious, and Cultural Conditions}

There are 56 ethnic minorities and 129 languages in China. Each language is a system of cultural codes of a minority. In areas with multiethnic settlements, although the language of other minorities can be understood and used in the process of economic, social, and cultural communication, every ethnic minority wishes to use only its own mother tongue to teach and learn when choosing the educational language. Moreover, in ethnic minority areas, if the number of school-aged children declines, those ethnic minority schools will not be willing to merge together although there is no traffic barrier or distance between them. In China, there are also many differences of faith between different religions or branches of the same religion. Religion matters in school consolidation.

\section{Neighborhood Safety}

The relationship between social safety and rural school consolidation can be understood using two dimensions. First, rural school consolidation may disrupt social order to some extent. Owing to rural school consolidation, the population in the countryside where a great number of schools are closed may decline considerably, and in those areas where schools are combined with other schools, the figure may rise considerably. Parents who want to take care of young children often live near schools, which may destroy the "Acquaintances Society" (or ShuRen SheHui, 熟人 
社会 $)^{15}$ and disrupt social safety. After rural schools are closed and consolidated, only old people remain in the village. Criminals may often commit crimes in those villages, such as burglary. What is more serious is that rural school consolidation may lead to many middle school dropouts. Some researchers found that in the village of Zhongyang county (Shanxi Province), social order was broken recently, and many crimes were committed by students who dropped out of middle schools, such as burglary and abduction (Hu and Que 2009).

Second, some societal factors may also pose a threat to students' safety. In boarding schools, because of poor management, there are many cases of people entering schools to hurt students. It happened in some areas students ran the risk of being attacked by criminals when they travelled a long distance to and from schools. Consequently, when governments promote rural school consolidation, they should also consider students' safety on their way to school or back.

\section{Family}

This refers to the status of rural families' daily lives and their main economic lifestyle. The livelihood of rural families is mainly traditionally based on farming, so the corresponding culture of rural school consolidation is "Cultivation and Reading" (or GengDu ChuanJia, 耕读传家). ${ }^{16}$ Hence, most rural schools are established near students' homes. In the grasslands, the main livelihood of rural families is the pasturage, so the corresponding culture of rural school consolidation is "nomadic education," such as "horseback school."17 In areas near rivers, the main economic livelihood of rural families is fishing, and those families often live on boats and float around. Therefore, the corresponding culture of rural school consolidation is "floating education," such as "ship school." With the rapid development of rural urbanization and the change of farmers' economic lifestyle, a growing number of rural residents are moving to cities to find jobs. Although the migration mode of rural workers has changed from single migration, to couple migration, to family migration, their hukou (户口) $)^{18}$ continues to remain in the countryside. After moving to

\footnotetext{
15 “Acquaintances Society” (or ShuRen SheHui, 熟人社会) is a concept used to explain the relationship among rural residents proposed by Xiaotong Fei, a famous sociologist in China, in his book From the Soil: The Foundations of Chinese Society. Fei argues that laws or rules are derived from the requirements of the modern society, because the modern society is organized by the cooperation between strangers. In contrast, in the countryside, residents are familiar with each other, and they believe each other, so they do not need laws to maintain the operation of communities and live in a peaceful environment (2012, p. 1-8).

16 “Cultivation and Reading” (or GengDu ChuanJia, 耕读传家) is a Chinese idiom. It means that in the countryside, traditionally, rural students should not only study books and master reading skills at schools but also study some agriculture skills at home. Thus, rural schools are often located near students' home, which is convenient for students to study.

17 "Horseback school" is a metaphor to explain the education in the grassland. "Ship school" in the next part is also a metaphor to explain the education in areas near rivers.

${ }^{18}$ Hukou (户口) refers to the household registration system that is used to register the population in China. Simply, different types of hukou determine where residents may live.
} 
cities, most rural workers live in the suburbs, and their children have to go to migrant schools or private schools that mainly serve those children. Those migrant children are a unique type of rural students, and protecting their rights to receive education is a vital issue that must be considered in rural school consolidation.

\section{Local Government Finance}

In order to allow more students to reach schools that are closer to their homes after school consolidation, many county or city governments have chosen to close old schools and establish new schools in different places or expanded boarding schools. Those measures may place a heavy fiscal burden on local governments (Liu et al. 2008). In fact, after school consolidation, local governments need to spend a huge amount of money to optimize the allocation of educational resources, improve the material conditions of school, and purchase new equipment or facilities. Overall, the cost of school consolidation is high. If the county or city government does not have an adequate fiscal budget, it will be difficult for them to achieve school consolidation.

\section{People's Will to Be Educated}

School consolidation may have a profound effect on people's educational interests. Promoting school consolidation should respect for farmers' will, which also reflects the procedural justice of school consolidation. Rural residents have a strong emotional attachment to their rural schools. Rural schools are not only a landmark building in the countryside but also a spiritual and meaningful symbol of the countryside. The reason why farmers do not want to close or consolidate schools is that they are worried not only that their children should travel a long distance to and from school and they need to afford the extra cost but also that their children may be bullied in other villages (Fan 2006). Some extremely notorious cases of school closure were usually caused by some local educational bureaus rarely seeking the opinions of villagers' committees, leaders of villages, and farmers in the process of school consolidation. They only announce that rural schools should be closed and consolidated, which arouses the strong opposition of farmers. In some villages, farmers even spontaneously set up a "school protection committee" to protect rural schools from closing or consolidating. "People oriented and respecting public opinion" are the basic value to be observed during school consolidation. Seeking public opinion may restrain the process of school consolidation, but it entails the standards of school consolidation. 


\subsubsection{Educational Constraints}

Educational constraints refer to the educational principle and the principle of running a school, fully considering what can allow school consolidation to perform a function in terms of improving the quality and benefits of education and promoting the development of students' mind and body. If those educational goals are not achieved, governments cannot close or consolidate schools arbitrarily.

\section{Students' Physical and Mental Development}

For most rural students, rural school consolidation means that they have to travel a longer distance to and from school. Senior students in primary schools and students in middle schools may adapt to the change of distance, but those young students aged 6-9 may suffer an injury and be negatively affected by a less-attentive environment. Those lead to a suggestion that young students are not suitable for studying and living in boarding schools, and the distance that students travel to and from school cannot be too long. Even if students can take the school bus to school, the traffic time of students in primary schools and in middle schools cannot exceed $30 \mathrm{~min}$ and $50 \mathrm{~min}$, respectively.

\section{Schools and Rural Communities}

If rural schools are closed and consolidated, the sense of commonality arising from rural schools in rural communities will be destroyed. As a result, the life of children will be separated from the community, which can damage the vitality of the community in turn. In fact, in a certain settlement space, from the point of view of students and parents, a school in the neighborhood has not only an educational function but also the symbolic function of suggesting that the area is highly inhabitable (Shi 2004). For rural communities, the disappearance of schools means the disappearance of ties that have symbolic meaning and hold the community together. Moreover, because of the increase in rural schools, rural communities may lose important social communication resources and become uninhabitable, which may aggravate the disintegration of rural communities and accelerate the outflow of rural population. As a result, rural communities will become "desert society." Therefore, rural school consolidation should consider the relationship between rural schools and rural communities, because rural schools are an organic part of rural society.

\section{School History and Culture}

Schools should be considered as animate instead of inanimate entities. For old schools with a long history, every building and thing associated with it represent a significant culture. If there is no school, there will be no hope for the countryside. 
Education is a "nerve system" of a nation and is also the best expression of a nation's tradition and expectation.

\section{Schooling Functions}

A school is called thus because it has a social function from the perspective of sociology. School is a place to perform schooling, especially the national curriculum standards. According to the Outlines of the Curriculum Reform in Basic Education (Trial) (基础教育课程改革纲要 (试行)) issued by the central government, the primary school needs to offer nine subjects, including Moral and Life (or Moral and Society), Chinese, Mathematics, Science, English, Comprehensive Practical Activity, Physical Education, Art (Music or Fine Arts), and Local Optional Course. ${ }^{19}$ From Grades 1 to 6, teachers in primary schools need to work for 6020 hours if they want to meet the requirement of the national curriculum. When we consider the full workload of $20 \mathrm{~h}$ /week for each teacher and 21 weeks of work/semester, a primary school needs at least 14 teachers so that it can fully perform the function of education. Moreover, if we consider the ratio between pupils and teachers (about 1:19) recommended in national documents, the minimum number of students in primary school should be 266. Middle schools should offer ten subjects, including Moral Education, Chinese, Mathematics, English, Science (Physics, Chemistry, or Biology), History and Society (or History and Geography), Sports and Health, Art (Music and Fine Arts), Comprehensive Practical Activity, and Local Optional Courses. The total amount of teaching work for 3 years (or from Grades 7-9) is $3502 \mathrm{~h}$. If each teacher takes $14 \mathrm{~h} /$ week and 21 weeks/semester to complete work, a middle school needs at least twelve teachers to complete the task of secondary education. Moreover, if we consider the ratio between students and teachers (about $1: 13.5-18$ ) in middle schools in national documents, the minimum number of students in middle school should be 162 . It is worth mentioning that the scale of middle schools can increase moderately, so the minimum number of students can rise considerably. If the teacher's weekly workload and the student-to-teacher ratio change, the minimum number of students will also change.

For a particular instance of rural consolidation, if there are conflicts between the twelve constraints mentioned above, the government should carefully consider those conditions that can perform the function without extra funds as the priority conditions. For example, compared to the condition of students' physical and mental development that is the compulsory condition and cannot be changed by other factors, the function of schools can be affected by narrowing the student-to-teacher ratio and increasing the number of bianzhi (编制). ${ }^{20}$ Therefore, governments should prioritize the condition of students' physical and mental development.

\footnotetext{
${ }^{19}$ Local optional course refers to those courses that are designed by schools or local governments, such as some courses that introduce the local culture.

${ }^{20} \mathrm{Bianzhi}$ (编制) is a kind of formal identity of an employee in schools and is also a kind of personnel management system. When teachers have bianzhi in public schools in China, it means they are
} 


\subsubsection{Design Proposal of Standards for Rural School Consolidation}

The process of designing standards for rural school consolidation with Chinese characteristics is equivalent to the process of achieving the satisfactory goal of school consolidation by working on the constraints identified by the local governments.

According to the extent to which involved stakeholders can modify the twelve constraints mentioned earlier, they can be classified into three categories. The first category includes those constraints that cannot be changed at a fundamental level such as the geographical conditions; the clan, ethnic, religious, and culture conditions; the conditions of students' physical and mental development; and the historical and cultural conditions of schools. These conditions should be regarded as the basic standard of school consolidation.

The second category includes those constraints that can be changed under certain conditions, such as the population condition, the conditions of family survival, the condition of people's will to be educated, and the relationship between schools and rural communities.

The third includes those constraints that can be changed completely, such as the traffic conditions, the condition of local governments' funds, the social security condition, and the function of schools. The second and third categories can be considered as the basis for determining "the first flexible standard" and "the second flexible standard" of rural school consolidation. These three categories are not divided absolutely, and they can overlap under certain conditions.

There are 2851 county-level administrative areas $^{21}$ in China. Because of the different conditions of those areas, such as the location, the developmental level of the economy, the urbanization rate, the natural resources and environment, the local cultural traditions, and residents' schooling year, the flexibility to modify the constraints of school consolidation is different. The national standard (GB3953.1-83) issued by the central government in 1983 refers to the unified rule of repeated things and concepts. Based on the comprehensive result of science, technology, and practical experience, the standard can be approved by authorities and issued in a specific form, as a common rule and foundation, after some relevant stakeholders reach an agreement. Since the complexity of school consolidation is higher than the complexity involved in formulating technological standards, it is impossible to design and issue a unified national standard. However, based on those constraints mentioned above, we can propose a new standard model composed of basic and flexible

formally employed by governments and can enjoy higher salaries and insurances. Public teachers require officially established positions to stay on the public payroll.

${ }^{21}$ According to the current administrative division of China, the county-level administrative areas include seven types, such as municipal districts in prefecture-level cities, county-level cities, counties, autonomous counties, autonomous counties (banners) in autonomous areas for ethnic minorities, special economic zones, and forest districts. 
parts that can be used as a reference for county and city governments when designing a plan of school closure and consolidation.

\subsubsection{Standards for Rural School Closure and Consolidation}

In the context of decrease in the total school-aged population, the first option of rural consolidation is to consolidate or close rural schools. Rural school closure and consolidation include two aspects: the first is to close or consolidate schools, and the second one is to reduce a school into an incomplete primary school or a smallscale school ${ }^{22}$ that is managed by a nearby complete primary school or central school.

The main objects of rural primary school consolidation are countryside primary schools and small-scale schools. Based on the principles of the changes of student population, the convenience of traffic, the similarity of culture, and the history of schools, local governments can close or consolidate some countryside primary schools and small-scale schools in a step-by-step manner and encourage some small-scale schools in those areas with inconvenient traffic and unsafe roads. Moreover, local governments can establish primary schools consisting of Grades 1-3 in every village, complete primary schools in some villages, and the central school in towns or townships. The primary boarding school does not require students who are in Grades 1-3 to get boarding in general.

Based on the Evaluation Indicators of Small-Scale Schools'Development issued by the Education Department of Taiwan $(\mathrm{CN})$, the author formulates a theoretical

\footnotetext{
${ }^{22}$ At the stage of primary education, there are five kinds of primary education organizations, such as the small-scale school, primary school consisting of Grade 1-3, complete primary school, incomplete primary school, and central school. The small-scale school refers to educational organizations that have only one teacher and consider teaching multigrade classroom as the main method. In recent years, with the deep reform of the system of small-scale schools, the small-scale schools with one teacher have changed significantly. Now teachers of small-scale schools are managed by the central school, and many teachers are required to serve small-scale schools. The primary school consisting of Grades 1-3 was derived from the primary school system (or RenZi Guichou school system, 壬子癸丑学制) in the period of the Republic of China. In this school system, the primary school was divided into two parts, namely, the primary school consisting of Grades 1-4 (or low-level primary school) that only served children aged 7-10 and the primary school consisting of Grades 5-8 (or high-level primary school) that served graduates of low-level primary school. Today, in order to ensure the scale of schools, some local governments may affiliate the preschool or kindergarten to the primary school consisting of Grades 1-3. The complete primary school refers to the primary school consisting of Grades 1-6 (or Grades 1-5 in some areas whose school system is 5 years), and every grade has normal classes with several teaching activities. In some remote areas, due to the inconvenience of transportation and lack of teachers, some primary schools have been able to only set up some grades, such as Grades 1-4 or 1-3. Therefore, those schools are called incomplete primary schools. Since the implementation of the educational management system based on the county government in 2001, the central primary school, also known as the central school, has been the only primary school in townships or towns that have been commissioned by the education bureau in a county or city to implement some administrative and educational research and perform the function of management and instruction.
} 
model for rural school consolidation. The core idea of this model is "basic standards + flexible standards" (see Table 1.13).

If primary schools meet any requirement of the basic standards, they cannot be closed or consolidated. The flexible standard is divided into two types, namely, "Flexible Standard I" and "Flexible Standard II." "Flexible Standard I" means that those schools who obtain a score of $40-60 \%$ of the total after a comprehensive evaluation can be changed into the small-scale school or a primary school offering Grades 1-3. "Flexible Standard II" means that those schools who score lower than $40 \%$ of the full score can be closed or consolidated.

Compared with rural primary schools, the pressure to consolidate rural middle schools is relatively small. Students in middle schools have better self-care abilities and health, and their emotional development or reliance on their families can be improved. Thus, local governments can expand the scale of middle schools and develop middle boarding schools. According to the new construction plan for towns or townships, every town or township is permitted to run a middle school in principle. Towns or townships whose population is over 40,000 can run two middle schools, and those whose population is less than 20,000 can run a 9-year school (including the primary school and the middle school). Based on the lowest scale of middle schools (about 162 students in middle school) calculated above, those middle schools can be consolidated if they meet the following requirements: first, middle schools having less than 3 classes, less than 150 students, poor conditions, and small developmental potential can be consolidated. Second, middle schools with an average score of less than 65 on the students' academic test can be consolidated. Third, a middle school whose number of school-aged children has declined noticeably, who cannot reach the lowest scale of students enrolled in schools, or whose service population is less than 15,000 can be consolidated.

\subsubsection{The Construction and Expansion Standard for Rural Schools}

According to the theoretical model proposed above, schools that do not comply with "the standard of reserving school" or "the standard of changing school's function or nature" can be rebuilt or expanded. The construction and expansion of schools can be designed based on the economics theory of school scale and the relevant flexible standard mentioned above. The construction and expansion of schools in the process of school consolidation should follow the economic logic of school scale owing to the following reasons.

First, the theory can exclude the interference of some flexible variables that are relevant to the standards for reserving school, such as geographical environment and traffic conditions, which means that the construction and expansion of schools can be designed according to the rational principle. Second, the utilization of schools' resources is characterized by "unity" or "inseparability." The unity of schools' resources means that the decline in the number of students may not lead to a reduction in the cost of the school land, the infrastructure, the equipment, and other resources. The inseparability of schools' resources means that some resources 


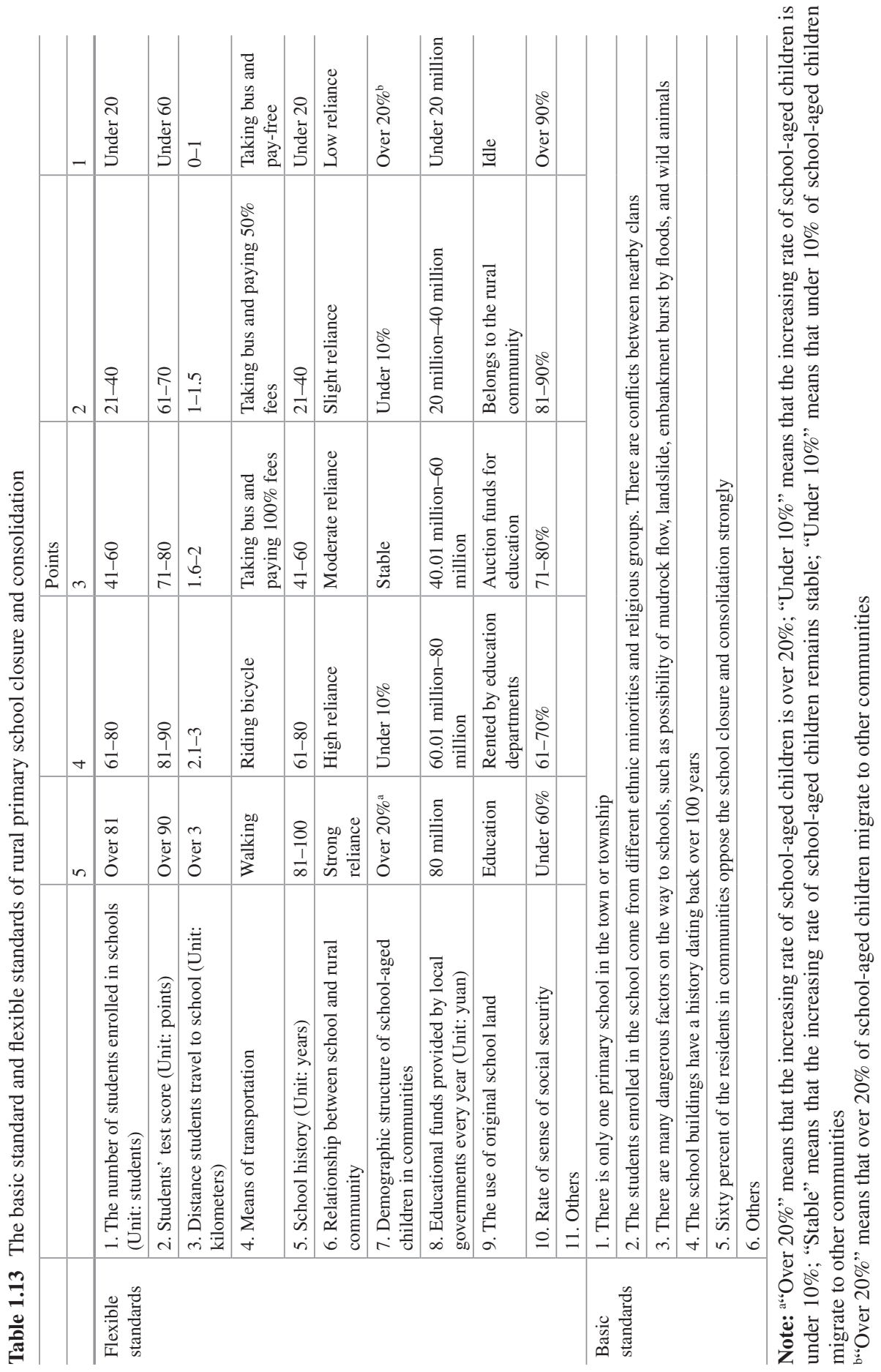


are used as a fixed unit, and they cannot be reduced when the requirement does not meet an expected limit, such as winter heating in classrooms. Third, the specialization of school teaching and management helps to improve the quality and efficiency of education. The increase in schools' scale can improve the problems caused by general teaching or multidisciplinary teaching and help promote the professional development of teachers. Because of the increase in the number of teachers' bian$z h i$, the principals can employ more school administrators according to relevant standards and promote the division and cooperation of labor and the specialization of school management. Fourth, the economics logic of school scale can help schools provide students with various courses or activities to meet their developmental needs of personality and increase the choice space and development opportunities.

The construction and expansion standard of rural school consolidation should consider the variables, including the region and population coverage by school, the scale of school (the number of classes per grade and the total number of classes), the allocation of resources, and the land area (or building area).

Excepting the standards for rural school consolidation, rural school consolidation also brings up further policy issues, such as the procedure justice, the scale of rural schools, and the equality of educational opportunity. Future studies can take up discussions of these important topics.

\section{References}

Fan, X. Z. (2006). Studies on the reason, motivity and pattern selection of adjusting primary and secondary school distribution in rural areas. Education \& Economy, 1, 27-29.

Fei, X. T. (2012). From the soil: The Foundations of Chinese Society. Beijing: Foreign Language Teaching and Research Press.

Hu, J. Z., \& Que, X. C. (2009). The positioning adjustment of rural primary and middle schools in the context of building the New Village construction. Journal of Yulin University, 19(2), $109-112$.

Hu, P. P., \& Zhang, S. X. (2007). Nongcun yiwu jiaoyu touru baozhang jizhi ji guanli tizhi wenti yanjiu [Research on the problem of the safeguard mechanism of the investment in rural compulsory education and the problem of management system of rural compulsory education]. Beijing: China Science Publishing \& Media Ltd (CSPM).

Liu, H. M., Na, R. G. W., \& Wang, S. (2008). Layout adjustment: The effective path to improve the overall quality of basic education. Journal of Northeast Normal University (Philosophy and Social Science), 1, 5-12.

National Bureau of Statistics of China. (2001-2017). Zhongguo tongji nianjian (2001-2017) [Statistics yearbook of China (2001-2017)]. Beijing: China Statistics Press.

National People's Congress. (1986). Zhonghua renmin gongheguo Yiwu jiaoyufa [The Compulsory Law of the People's Republic of China]. Beijing: China Law Publishing House.

National People's Congress. (2006). Zhonghua renmin gongheguo Yiwu jiaoyufa [The Compulsory Law of the People's Republic of China]. Beijing: China Law Publishing House.

Pang, L. J. (2006). Rural primary and secondary consolidation: Problems, reasons and strategies. Research in Educational Development, 4, 7-12.

Shi, R. B. (2004). Studying on adjusting school distribution abroad and its enlightenment on China. Comparative Education Review, 12, 35-39. 
State Council. (1993). Zhongguo jiaoyu gaige yu fazhan gangyao [Outline of China's Educational Reform and Development]. Retrieved February 13, 1993, from http://old.moe.gov.cn//publicfiles/business/htmlfiles/moe/moe_177/200407/2484.html

State Council. (2001). Guanyu jichu jiaoyu gaige yu fazhan de jueding [The Decision on the Reform and Development of Elementary Education]. Retrieved May 29, from http://old.moe. gov.cn/publicfiles/business/htmlfiles/moe/moe_719/200409/3843.html

State Council. (2012). Guanyu guifan nongcun yiwu jiaоyи хиехiao buju tiaozheng de yijian [The opinions on regulating the closure and consolidation of rural compulsory schools]. Retrieved September 6, from http://www.gov.cn/zwgk/2012-09/07/content_2218779.htm

State Council. (2018). Guanyu quanmian jiaqiang xiangcun xiaoguimo xuexiao he xiangzhen jisuzhi xuexiao jianshe de zhidao yijian [The opinions on comprehensive strengthening the construction of small-scale schools in the countryside and boarding schools in the town or township]. Retrieved April 25, from http://www.gov.cn/zhengce/content/2018-05/02/content_5287465.htm

The Department of Development \& Planning, Ministry of Education. (2001-2017). Zhongguo jiaoyu tongji nianjian (2000-2016) [Educational statistics yearbook of China (2000-2016)]. Beijing: People's Education Press.

Zhihui Wu professor of education and the dean of Graduate School and China Institute of Rural Education Development at Northeast Normal University. He is a distinguished professor of Cheung Kong Scholars Program, a member of Ten Thousand Leaders Plan of Philosophy and Social Sciences. He also serves as the director of Rural Education Branch of the Chinese Society of Education and the deputy director of Learning Science Research Branch of the Chinese Association of Higher Education. He has completed over 20 research projects, including the Key Project of Philosophy and Social Sciences funded by Ministry of Education and has published over 240 journal articles and 10 books. E-mail: wuzh@ nenu.edu.cn.

Open Access This chapter is licensed under the terms of the Creative Commons Attribution 4.0 International License (http://creativecommons.org/licenses/by/4.0/), which permits use, sharing, adaptation, distribution and reproduction in any medium or format, as long as you give appropriate credit to the original author(s) and the source, provide a link to the Creative Commons licence and indicate if changes were made.

The images or other third party material in this chapter are included in the chapter's Creative Commons licence, unless indicated otherwise in a credit line to the material. If material is not included in the chapter's Creative Commons licence and your intended use is not permitted by statutory regulation or exceeds the permitted use, you will need to obtain permission directly from the copyright holder.

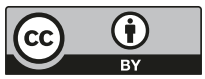

